texts are often more valued as objects and sites of research than research coming from periphery areas. To respond to the growing institutional and governmental pressures to publish in English-medium outlets, multilingual scholars writing from the periphery may need support in the form of bibliographic resources and guidance on shaping manuscripts to meet the conventions of particular journals. Scholars from the periphery may also need support in finding ways to collaborate with scholars in center contexts. At the same time, center gatekeepers should examine the preferences given to particular research contexts, topics, and questions.

Second, English-medium publications increasingly function as criteria for a range of institutional evaluations of individual scholars, their departments, their institutions, and research grant awards. While using English-medium publications as a marker of quality may offer policymakers the sense of creating uniform standards, such policies may not take into account the challenges facing scholars. Such policy innovations are not always accompanied by the resources needed to support scholars in attaining these goals. Discussions of English-language dominance therefore need to be placed on policy agendas for international higher education.

As the academic sphere becomes increasingly globalized,

Anglophone contexts are often more valued as
objects and sites of research than research coming
from periphery areas.

the question of linguistic imperialism and the premium of English in scholarly publishing needs to become a topic of discussion at international and national governmental and institutional levels. These discussions should include raising awareness of how native English speakers or those working in Anglophone contexts are highly advantaged in the global academic marketplace compared with multilingual scholars writing from the periphery. Questions about the effects that privileging English may have on the evolution of local languages, particularly the development of academic registers, and on local research cultures should also be explored further. While the dominance of English as an academic lingua franca is unlikely to shift in the near future, consideration can be given to ways to renegotiate the conditions under which global knowledge is produced and disseminated. Under globalization, the multidirectional circulation of knowledge from academic research has greater potential for benefit than does a unidirectional flow outward from Anglophone countries.

\section{Mobilizing Marginalized Talent: The International Fellowships Program}

\section{JÜRGEN ENDERS}

Jürgen Enders is professor at and director of the Center for Higher Education Policy Studies (CHEPS), University of Twente, Enschede, the Netherlands. Address: CHEPS, University of Twente, POB 217, 7500 AE Enschede, Netherlands. E-mail: j.enders.utwente.nl.

Tn November 2000, the Ford Foundation and the International Institute of Education created the International Fellowships Program (IFP) to provide graduate fellowships for individuals from 22 countries in the "Global South." This I2-year, \$280 million program is the largest initiative in the foundation's history and has recently been extended by another 2 years and $\$ 75$ million in supplementary funds. IFP gives talented students from excluded or marginalized backgrounds the opportunity for advanced study in universities at home and abroad. In 2002, CHEPS was asked to implement an evaluation of the program regarding its implementation and development.

\section{A Different Approach}

IFP supports mobile scholarships of up to three years of postgraduate study at accredited universities anywhere in the world in a variety of academic fields so that students may choose where and what to study. Fellowships are reserved for talented individuals from the South lacking systematic access to higher education for reasons such as poverty, geographical isolation, ethnicity, race, or gender. The program defines its target group of undergraduates based on their leadership potential, commitment to the development of their countries or communities, as well as academic performance and potential. The fellows, through their further training and scholarly work, are expected to contribute to academic fields relevant to the economy and social justice and to take a leadership role in these areas in their own countries and worldwide.

An innovative and challenging approach has been chosen for IPF: finding and attracting bright students from marginalized backgrounds in the South for international graduate work who want to make a difference in their societies.

\section{CHEPS FINDINGS}

Surveys and interviews by CHEPS show that the IFP has so far been successful in the implementation and development of the program. IFP has received nearly I0०,000 applications in the competitions of 200I-2005. In addition to fulfilling unmet demand and potential among excluded communities and groups, IFP attracts and mobilizes interest in regions ranging from the Anambra State in Southeastern Nigeria, to the Mixtec 
Indian community in Mexico, and to China's Guizhou Province.

The program mainly recruits fellows from among people with a sociodemographic and sociobiographic profile that fits the program's goals. The target group criteria of "exclusion" and certain regional and local contexts are well reflected in the profile of the fellows. About 90 percent of them are first-generation students with a poor socioeconomic background who had to overcome experience of social injustice to achieve their undergraduate studies. IFP supports the fellows through various voluntary and paid community services as well as related leadership activities in a broad range of areas including community-based organizations, social movements, and nongovernmental organizations.

The program offers pre-placement training and support to study at more than 400 universities in some 40 countries. Surveys among fellows - most of them outside their countries for the first time-show that they highly value their postgraduate study experience and maintain contact with their home communities while building up a network that includes other IFP fellows. The graduation rate of IFP alumni is 85 percent, and so far 75 percent of them have returned to their home countries while most of the others continue their studies or go for further studies/training abroad.

\section{FACTORS OF SUCCESS}

The IFP can rely on a financial commitment made via the establishment of the International Fellowship Fund. The biggest postgraduate fellowship program ever, the program needed to establish structures and processes on a global scale that focus at the same time on local context. This achievement would probably have been impossible without a substantial and long-term financial commitment.

IFP has created a worldwide partnership of organizations around its central unit in New York. This partnership involves 20 organizations in the IFP countries or regions (e.g., the Association of African Universities, the Indonesian International Education Foundation, and the Economic and Social Research Foundation in Tanzania), international placement partners (e.g., the Institute of International Education, NUFFIC in the Netherlands, and the British Council) as well as strategic partnerships with certain universities. Global outreach and local presence are thus based on a network of organizations, building upon their expertise and contacts.

The IFP has not developed a detailed standard framework to carry out its target group criteria on a global scale. Instead, it has set up an intense and ongoing process of consultation in each country and region to discuss the nature of access to higher education and to identify target groups and communities that lack access. In this process certain cultural, social, and economic indicators of exclusion have been identified as priorities for country or subregion. Techniques were discussed and implemented for the outreach of the IFP to the respective target groups. Ongoing exchange on "lessons learned" and "good practice" forms part and parcel of the challenging further development of this global/local program.

What IFP will achieve in the long run needs to be examined-for example, by studying the progress of the alumni and growing networks. The IFP's experiences and established practices will represent information of great interest concerning international student exchange and sustainable development on a global scale.

\section{Internationalization Brings Important Benefits as Well as Risks}

JANE KNIGHT

Jane Knight is adjunct professor at the Comparative, International and Development Education Centre, Ontario Institute for Studies in Education, University of Toronto. E-mail: janeknight@sympatico.ca.

W hile the process of internationalization affords many benefits to higher education, it is clear that there are serious risks associated with this complex and growing phenomenon. According to the results of the 2005 International Association of Universities (IAU) Survey there is overwhelming agreement ( 96 percent of responding institutions from 95 countries) that internationalization brings benefits to higher education. Yet, this consensus is qualified by the fact that 70 percent also believe there are substantial risks associated with the international dimension of higher education. (Information on the 2005 IAU Global Survey Report on the Internationalization of Higher Education: New Directions, New Challenges is available atiau@unesco.org.)

The top three risks associated with internationalization are commercialization and commodification of education programs, the increase in the number of foreign "degree mills" and low-quality providers, and brain drain. It is a sign of the times that each of these risks relates more to the cross-border aspects of internationalization than the campus-based activities. It is somewhat surprising that both developing and developed countries identified commercialization as the numberone risk over brain drain-a clear testimony to its importance.

It is also revealing that the loss of cultural or national identity, jeopardy of the quality of higher education, and the homogenization of curriculum were identified as the least important risks. When these results are compared to a similar 2003 IAU Internationalization Survey, brain drain was considered as the greatest risk. Thus, we are seeing a definite shift 